\title{
Mobility of redox sensitive elements in subduction zone, a Fe isotope study of Mariana forearc serpentinites
}

\author{
BAPTISTE DEBRET ${ }^{1}$, NADINE D MATTIELLI ${ }^{2}$, \\ BENEDICTE MENEZ ${ }^{1}$, IVAN SAVOV ${ }^{3}$ AND HELEN M \\ WILLIAMS $^{4}$ \\ ${ }^{1}$ Université de Paris, Institut de physique du globe de Paris, \\ CNRS UMR 7154 \\ ${ }^{2}$ Université Libre de Bruxelles \\ ${ }^{3}$ University of Leeds \\ ${ }^{4}$ University of Cambridge \\ Presenting Author: debret@ipgp.fr
}

Subduction zones are active sites of chemical exchange between the Earth's surface and deep interior and play a fundamental role in regulating planet habitability. However, the mechanisms by which redox sensitive elements (e.g., iron, carbon and sulfur) are cycled during subduction remains unclear. Here we use Fe stable isotopes $(\delta 56 \mathrm{Fe})$, which are sensitive to redox-related processes, to examine forearc serpentinite clasts recovered from deep sea drilling of mud volcanoes formed above the Mariana subduction zone in the Western Pacific. We show that serpentinisation of the forearc by slab-derived fluids produces dramatic $\delta 56 \mathrm{Fe}$ variation. Unexpected negative correlations between serpentinite bulk $\delta 56 \mathrm{Fe}$, fluid-mobile element concentrations (e.g., $\mathrm{B}, \mathrm{As})$ and $\mathrm{Fe} 3+/ \Sigma \mathrm{Fe}$ suggest a concomitant oxidation of the mantle wedge through the transfer of isotopically light iron by slab-derived fluids. This process must reflect the transfer of either sulfate- or carbonate-bearing fluids that preferentially complex isotopically light $\mathrm{Fe}$. 